\title{
APHASIA IN THE COGNITIVE DISORDERS CONTEXT - PRELIMINARY STUDY
}

\author{
Lucie Šebková \\ Kateřina Vitásková \\ Faculty of Education, University of Palacký in Olomouc, Czech Republic
}

\begin{abstract}
Purpose: The aim of the article is to analyse cognitive disorder in persons with aphasia of various aetiology pursuant to brain damage, emphasizing the interdisciplinary cooperation between the professionals of speech therapy and psychology.

Methodology: Seven persons with stroke related aphasia of different aetiology participated in the research. For data processing, psychological, neurological and speech therapeutic detailed reports were applied.

Results: We observed higher incidence of ischaemic stroke than haemorrhagic stroke. Expressive aphasia occurred in 6 of the 7 clients. Attention disorder and thinking disorder occurred in almost all 6 of the clients. Executive functions were impaired in 5.

Conclusion: Given our findings, we tend to aphasia therapy in terms of cognitive rehabilitation. We perceive the interdisciplinary cooperation with specialists from the field of psychology as absolutely necessary. The results of psychological examination of persons with aphasia can significantly influence the effectiveness of speech therapy intervention.
\end{abstract}

Keywords: aphasia, cognitive disorder, interdisciplinary cooperation, stroke.

\section{Introduction}

The role of non-linguistic disorder is more-often-than-not disregarded in speech-therapeutic interventions and speech therapists are often directed merely by the results of language tests even though people with aphasia show a high rate of variability in cognitive processes, given that the negative influence of non-linguistic disorders of cognitive functions was proven in the therapies of aphasia (Seniów et al., 2009). For this reason, the objective of the research examination is to analyse non-linguistic disorders of cognitive functions in people with aphasia of various aetiology pursuant to brain damage. The research examination took place in the Centre for Cognitive Disorders of the University hospital in Ostrava, Czech Republic and the professional neurological, psychological and speech-therapeutic reports from examinations of individual research participants were used for data processing. The objective of the preliminary study was to point out not only the non-linguistic disorders of cognitive functions in people with aphasia but also the necessity of interdisciplinary cooperation between speech therapists and psychologists. 


\section{Relationship of aphasia and disorders of cognitive functions}

The origin of intensive examination of a link between language disorder (aphasia) and cognitive disorders dates back to the $80 \mathrm{~s}$ of the $20^{\text {th }}$ century (Vukovic et al., 2008). The study of cognition in severe aphasia is, for example, applied in the research of the necessity of language in various areas of thinking (Bek et al., 2010).

At present, on the one hand we can encounter opinions that language disorder is manifested by a disorder of cognition (Baldo et al., 2005). These statements are supported by model situations specifying an integral relationship between speech and other domains of cognitive functions in people with or without speech disorder (Murray, 2012). Kalbe et al. (2005) identified significant correlation between a sub-test focused on visual attention and two other linguistic sub-tests (understanding of a read text and speech fluency). On the other hand, there are researches at disposal that did not detect, in people with aphasia, any significant link between linguistic and non-linguistic abilities of attention, memory, executive functions and visuospatial abilities (HelmEstabrooks, 2002; Hickley \& Nash, 2007; Vukovic et al., 2008, Nicholas et al., 2011).

In general, we can observe an individual profile of non-linguistic damage from which it can be deduced that it is not possible to foresee a condition of non-linguistic cognitive abilities on the basis of a condition of language abilities (Helm-Estabrooks, 2002; Seniów et al., 2009; Murray, 2012).

Prevalence of non-linguistic cognitive disorders in aphasia after stroke was observed by Hachioui et al. (2014) in their study. Out of the total amount of 147 patients, a cognitive disorder was proven in at least one non-linguistic domain in 107 patients $(88 \%)$ three months after stroke and in 91 patients $(80 \%)$ one year after stroke. Higher probability of deficiency in cognitive functions is associated with damage to the left hemisphere, cortical lesion and ictus in the medial cerebral artery (Cumming et al., 2013).

The need to evaluate the non-linguistic cognitive abilities in people with aphasia is highlighted for reason of maximizing the benefit of therapy (Votruba et al., 2013; Zakariás et al., 2013; Hachioui et al., 2014). Deficiencies in one of the non-linguistic cognitive areas can disturb not only the process of renewal of speech abilities but also the process of coping with the handicap (Seniów et al., 2009). Negative impact of, especially, disorders of attention and executive functions on the therapy of aphasia is mentioned, among others, in the studies by Brownsett et al. (2014) and Ramsbergera (2005), claiming that the rehabilitation of these cognitive functions, even in people with chronic aphasia, can lead to apparent changes in these abilities. The components of executive functions seem to be important for initialization of a new theme, planning and controlling of our communication performance, including changes in communication strategies, which results in successful delivery of information (Ramsberger, 2005). 
Vukovic et al. (2008) draw attention to the condition of memory in people with aphasia which is, according to the results of their research, a significant prognostic factor of aphasia and correlates with revival of the language functions. A rather significant prognostic factor of aphasia seems to be, above all, the aetiology. Published studies indicate that aphasia occurring as an aftereffect of cerebral trauma have better prognosis than aphasia occurring after a stroke (Vukovic, 1998; Laska et al., 2001; Vukovic et al., 2008).

\section{Methodology}

In total, 7 adult people with aphasia as a result of stroke of various aetiology participated in the research examination. The excluding criterion was aphasia in acute phase and aphasia that did not occur as a result of stroke or the presence of dementia. The research sample included 4 women and 3 men, average age 56.43 years.

In order to carry out objective data processing, which would indicate a disorder of cognitive function in people with aphasia, a detailed report from a psychologist was used together with a report from a neurologist or a speech therapist. The following methods were used for psychological diagnosis: Addenbrooke's cognitive test (ACER), selected sub-tests of Wechsler intelligence scale for adults (WAIS-III), Trail Making Test, Rey-Osterrieth complex figure test, and observation and dialogue. Based on the report of a speech therapist or a neurologist, the type of aphasia was identified. For our purpose, only a dichotomous classification was applied for distinguishing between expressive and receptive aphasia.

The following research questions were set for the selected research sample of people with aphasia:

1) Do you observe the presence of non-linguistic disorders of cognitive functions?

2) What is the frequency of occurrence of individual non-linguistic disorders of cognitive functions?

\section{Data analysis}

We decided to record the results acquired from the research in the form of tables. We recorded general information referring to gender, age, and the type of stroke and aphasia (Tab. 1). Other tables show specific information relating to individual clients: the results of Addenbrooke's cognitive test (Tab. 2) and evaluation of cognitive functions (Tab. 3). We evaluated, in all clients, the following domains of cognitive functions: attention, memory, executive functions, thinking (bradypsychism) and visuospatial abilities. We did not focus on individual components of cognitive abilities. In the event of detecting a deficit in the client's cognitive function, we allocated the "plus" sign. The 
"minus" sign indicated absence of a disorder. In case a domain was not evaluated in a client, we gave him/her the " $x$ " sign.

Table 1. General information about clients

\begin{tabular}{|c|c|c|c|c|}
\hline Patient & Sex & $\begin{array}{c}\text { Year of } \\
\text { Birth }\end{array}$ & Neurological Diagnosis & $\begin{array}{c}\text { Speech-therapy } \\
\text { Diagnosis }\end{array}$ \\
\hline P1 & Woman & 1982 & Intracerebral bleeding F-T left & Expressive phatic disorder \\
\hline P2 & Woman & 1971 & ischemic CVA left & Expressive phatic disorder \\
\hline P3 & Man & 1952 & ischemic CVA left & Expressive phatic disorder \\
\hline P4 & Woman & 1941 & ischemic CVA left & Expressive phatic disorder \\
\hline P5 & Man & 1948 & $\begin{array}{c}\text { Lacunar stroke in the left carotid } \\
\text { area }\end{array}$ & Expressive phatic disorder \\
\hline P6 & Man & 1964 & ischemic CVA left & Expressive phatic disorder \\
\hline P7 & Woman & 1945 & Intracerebral bleeding T left & Sensory phatic disorder \\
\hline
\end{tabular}

Table 2. Results of Addenbrooke's cognitive test

\begin{tabular}{|c|c|c|c|c|c|c|c|}
\hline Patient & MMSE & ACER & $\begin{array}{c}\text { Attention } \\
\text { and } \\
\text { orientation }\end{array}$ & Memory & $\begin{array}{c}\text { Verbal } \\
\text { production }\end{array}$ & $\begin{array}{c}\text { Langu } \\
\text { age }\end{array}$ & $\begin{array}{c}\text { Visually } \\
\text { spatial } \\
\text { abilities }\end{array}$ \\
\hline P1 & $28 / 31$ & $73 / 101$ & $18 / 18$ & $15 / 26$ & $1 / 14$ & $23 / 26$ & $16 / 16$ \\
\hline P2 & $\mathrm{X}$ & $\mathrm{X}$ & $\mathrm{x}$ & $\mathrm{X}$ & $\mathrm{X}$ & $\mathrm{X}$ & $\mathrm{X}$ \\
\hline P3 & $\mathrm{X}$ & $\mathrm{X}$ & $\mathrm{x}$ & $\mathrm{X}$ & $\mathrm{x}$ & $\mathrm{X}$ & $\mathrm{X}$ \\
\hline P4 & $22 / 30$ & $59 / 100$ & $13 / 18$ & $13 / 26$ & $1 / 14$ & $21 / 26$ & $11 / 16$ \\
\hline P5 & $10 / 30$ & $28 / 100$ & $6 / 18$ & $6 / 26$ & $5 / 14$ & $9 / 26$ & $2 / 16$ \\
\hline P6 & $\mathrm{X}$ & $\mathrm{X}$ & $\mathrm{x}$ & $\mathrm{x}$ & $\mathrm{x}$ & $\mathrm{X}$ & $\mathrm{X}$ \\
\hline P7 & $11 / 30$ & $32 / 100$ & $5 / 18$ & $0 / 26$ & $0 / 14$ & $11 / 26$ & $16 / 16$ \\
\hline
\end{tabular}

Table 3. Evaluation of cognitive functions

\begin{tabular}{|c|c|c|c|c|c|}
\hline Patient & Attention & Memory & $\begin{array}{c}\text { Executive } \\
\text { functions }\end{array}$ & $\begin{array}{c}\text { Thinking } \\
\text { (bradypsychism) }\end{array}$ & $\begin{array}{c}\text { Visuospatial } \\
\text { abilities }\end{array}$ \\
\hline P1 & + & - & + & + & - \\
\hline P2 & - & - & $\mathrm{x}$ & + & + \\
\hline P3 & + & + & $\mathrm{x}$ & + & $\mathrm{x}$ \\
\hline P4 & + & $\mathrm{x}$ & + & - & + \\
\hline P5 & + & + & + & + & + \\
\hline P6 & + & + & + & + & - \\
\hline P7 & + & $\mathrm{x}$ & + & + & - \\
\hline
\end{tabular}

\section{Results}

From table 1 (Tab. 1), more frequent occurrence of ischemic stroke (4/7 people) compared with haemorrhagic stroke ( $2 / 7$ people) can be deduced. We can also observe the presence of expressive phatic disorder almost in all clients $(6 / 7)$. 
Table 2 (Tab. 2) shows the results of Addenbrooke's cognitive test. In principle, this is a neuropsychological screening battery applicable in the early detection of cognitive disorders and for identifying the level of cognitive functions (Mathuranath et al., 2007; Raisová et al., 2011). The presented results might indicate the presence of dementia in 2 out of 7 patients. With respect to the presence of aphasia, this conclusion is not correct. In our opinion, the application of the Addenbrooke's cognitive test is not objective and relevant for evaluating cognitive functions in people with aphasia:

- $\quad 3 / 7$ clients were not able to conduct the test,

- $\quad 2 / 7$ clients fall in the category of moderate dementia,

- $\quad 1 / 7$ clients fall in the category of mild dementia,

- $\quad 1 / 7$ client is within the norms.

The results do not correspond with the reality and rather indicate the significance of the phatic disorder because almost all sub-tests require verbal production or undisturbed understanding of speech.

Table 3 (Tab. 3) shows the presence of cognitive deficits in aphasia in domains other than linguistic. Disorder of attention and thinking occur in almost all clients (6/7). Executive functions were disturbed in 5/7 clients, in 2/7 clients it was not possible to express a clear opinion on these functions. Disturbance in the area of memory and visuospatial abilities seems to be more varied.

Clients P1 and P7 suffered haemorrhagic stroke with almost identical localization (left temporal and frontal-temporal). We can observe the comparable distribution of disorders of cognitive functions (Tab. 4). Only these two clients achieved 16/16 points in the domain "visuospatial abilities" in the ACER test.

Table 4. Distribution of disorders of cognitive functions in haemorrhagic stroke

\begin{tabular}{|l|l|l|l|l|l|}
\hline Patient & Attention & Memory & $\begin{array}{l}\text { Executive } \\
\text { function }\end{array}$ & $\begin{array}{l}\text { Thinking } \\
\text { (bradypsychism) }\end{array}$ & $\begin{array}{l}\text { Visuospatial } \\
\text { abilities }\end{array}$ \\
\hline P1 & + & - & + & + & - \\
\hline P7 & + & $\mathrm{x}$ & + & + & - \\
\hline
\end{tabular}

\section{Responses to the research questions:}

1) Do you observe presence of non-linguistic disorders of cognitive functions?

In selected people with aphasia, disorders of non-linguistic cognitive functions are detected in more than one domain.

2) What is the frequency of occurrence of individual non-linguistic disorders of cognitive functions?

Most frequently occurring, in selected people with aphasia, were the disorders of attention and thinking (6/7 people). Disorders of executive 
functions were present in 5/7 people. Disorders of memory and visuospatial abilities were monitored in $3 / 7$ people with aphasia.

\section{Conclusion}

The fact that there is an indisputable correlation between cognition and language requires including all cognitive abilities of a patient in the process of rehabilitation following cerebral damage. Speech therapy of people with aphasia should incorporate also therapy of non-linguistic cognitive functions. Therefore, interdisciplinary cooperation with professionals from psychology is considered as essential. The results of psychological examination in people with aphasia can significantly influence the effectiveness of speech-therapeutic intervention if we take into consideration the findings about the impact of disorders of cognitive functions on the therapy of aphasia:

- Disorder of attention can result in disturbance in data processing regardless.

- In speech therapy, it is possible to apply all types of teaching methods supported by memory processes.

- Visuospatial abilities are blended in the entire intervention (recognition of pictures, letters, etc.).

- Communication ability in every-day unpredictable situations requires flexible solution to a problem, i.e. undisturbed executive functions.

The results of speech-therapeutic examination can, on the contrary, influence the compilation of a plan for cognitive rehabilitation of people with aphasia in order to maintain consistency in practising cognitive functions, and thus contribute to the rehabilitation of the most damaged phatic function.

\section{Acknowledgments}

The research results constitute partial results of the specific research 'Research on selected disorders and differences of communication ability with focus on the specifics of speech and language therapy and special education for hearing impaired assessment and intervention'. (IGA_PdF_2015_024, principal researcher: Kateřina Vitásková).

\section{References}

Baldo, J., V., Dronkers, N., F., Wilkins, D., Ludy, C., Raskin, P., \& Kim, J. (2005). Is problem solving dependent on language? Brain and Language, 92(3), 240-250.

Bek, J., Blades, M., Siegal, M., \& Varley, R. (2010). Language and Spatial Reorentation: Evidence From Severe Aphasia. Journal of Experimental Psychology: Learning, Memory, and Cognition, 36(3), 646-658.

Brownsett, S. L. E., Warren, J. E., Geranmayeh, F., Woodhead, Z., Leech, R., \& Wise, R. J. S. (2014). Cognitive control and its impact on recovery from aphasic stroke. Brain, 137(1), 242-254.

Cumming, T. B., Marshall, R. S., \& Lazar, R. M. (2013). Stroke, cognitive deficits, and rehabilitation: still an incomplete picture. International Journal of Stroke, 8(1), 38-45. 
Helm-Estabrooks, N. (2002). Cognition and aphasia: a discussion and a study. Journal of Communication Disorders, 35(2), 171-186.

Hachioui, H., Visch-Brink, E., G., Lingsma, H., F., Van de Sandt-Koenderman, M., W., Dippel, D., W., Koudstaal, P., J., \& Middelkoop, H., A. (2014). Nonlinguistic cognitive impairment in poststroke aphasia: a prospective study. Neurorehabil Neural Repair, 28(3), 273-281.

Hinckley, J., \& Nash, C. (2007). Cognitive assessment and aphasia severity. Brain and Language, 103(1-2), 195-196.

Kalbe, E., Reinhold, N., Brand, M., Markowitsch, J., \& Kessler, J. (2005). A new test battery to assess aphasic disturbances and associated cognitive dysfunctions: German normative data on the Aphasia Check List. Journal of Clinical and Experimental Neuropsychology, 27(7), 779-794.

Laska, A., C., Hellblom, A., Murray, V., Kahan, T., \& Von Arbin, M. (2001). Aphasia in acute stroke and relation to outcome. Journal of Internal Medicine, 249(5), 413-422.

Mathuranath, P. S. Cherian, J. P, Mathew, R., George, A., Alexander, A., \& Sarma S. P. (2007). Mini Mental State Examination and the Addenbrooke's Cognitive Examination: Effect of education and norms for a multicultural population. Neurology India. 55(2), 106-110.

Murray, L. L. (2012). Attention and Other Cognitive Deficits in Aphasia: Presence and Relation to Language and Communication Measures. American Journal of SpeechLanguage Pathology, 21, 51-64.

Nicholas, M., Sinotte, M., \& Helm-Estabrooks, N. (2011). C-Speak Aphasia alternative communication program for people with severe aphasia: Importance of executive functioning and semantic knowledge. Neuropsychological Rehabilitation, 21(3), 322366.

Raisová, M. et al. (2011). Addenbrookský kognitivní test a jeho možnosti použití v lékařské praxi. Psychiatrie, 15(3), 145-150.

Ramsberger, G. (2005). Achieving conversational success in aphasia by focusing on nonlinguistic cognitive skills: A potentially promising new approach. Aphasiology, 19(1011), 1066-1073.

Seniów, J., Litwin, M.,\& Leśniak, M. (2009). The relationship between non-linguistic cognitive deficits and language recovery in patients with aphasia. Journal of the Neurological Sciences, 283, 91-94.

Votruba, K., L., Rapport, L., J., Whitman, R., D., Johnson, A., \& Langenecker, S. (2013). Personality Differences among Patients with Chronic Aphasia Predict Improvement in Speech-Language Therapy. Top Stroke Rehabil, 20(5), 421-431.

Vukovic, M. (1998). Traumatic aphasia (in Serbian). Belgrade: Faculty of Special Education and Rehabilitation.

Vukovic, M., Vuksanovic, J., \&Vukovic, I. (2008). Comparison of the recovery patterns of language and cognitive functions in patients with post-traumatic language processing deficits and in patients with aphasia following a stroke. Journal of Communication Disorders, 41(6), 531-552.

Zakariás, L., Keresztes, A, Demeter, G., \& Lukács, A. (2013). A specific Pattern of executive dysfunctions in trancortical motor aphasia. Aphasiology, 27(12), 1426-1439. 